\title{
Identification of Sources of Resistance for Peanut Aspergillus flavus Colonization and Aflatoxin Contamination
}

\author{
Richard Moise Alansou Dieme $\mathbb{D}^{1},{ }^{1}$ Issa Faye, ${ }^{2}$ Yedomon Ange Bovys Zoclanclounon, ${ }^{3}$ \\ Daniel Fonceka, ${ }^{3}$ Ousmane Ndoye, ${ }^{4}$ and Papa Madiallacke Diedhiou ${ }^{1}$ \\ ${ }^{1}$ Université Gaston Berger, BP 211 Saint-Louis, Senegal \\ ${ }^{2}$ Centre National de Recherches Agronomiques de Bambey, Institut Sénégalais de Recherches Agricoles, BP 211 Bambey, Senegal \\ ${ }^{3}$ Centre d'Etudes Régional pour l'Amélioration de l'Adaptation à la Sécheresse, Route de Khombole, BP 3320 Thiès, Senegal \\ ${ }^{4}$ Conseil Ouest et centre Africain pour la Recherche et le Développement Agricoles, Avenue Bourguiba, BP 48 Dakar RP, Senegal
}

Correspondence should be addressed to Richard Moise Alansou Dieme; alansou7dieme@gmail.com

Received 25 May 2018; Revised 7 August 2018; Accepted 13 September 2018; Published 1 October 2018

Academic Editor: Glaciela Kaschuk

Copyright (c) 2018 Richard Moise Alansou Dieme et al. This is an open access article distributed under the Creative Commons Attribution License, which permits unrestricted use, distribution, and reproduction in any medium, provided the original work is properly cited.

\begin{abstract}
Peanut aflatoxin contamination caused by Aspergillus flavus is a serious constraint for food safety and human health in Senegal. The present study aimed to identify sources of resistance for A. flavus colonization and aflatoxin contamination. Thus, seeds from 67 peanut genotypes were tested under laboratory conditions. Aqueous conidial suspension of an aflatoxinogenic strain of $A$. flavus was used for inoculation in Petri dishes containing ten seeds of each genotype, and data on incidence and severity were recorded. Total aflatoxin concentration in seeds was determined on 15th day after inoculation using mReader ${ }^{\circledR}$ method. Results showed a significant $(p<0.001)$ variation of aflatoxin, incidence and severity among the tested peanut genotypes. Incidence ranged from 0 to $70 \%$ with a mean of $20.36 \pm 0.8 \%$. Out of the 67 genotypes, eight showed incidence less than $10 \%$. Severity ranged from 0 to $44 \%$ with a mean value of $8.82 \pm 0.45 \%$. The genotype 12CS_104 showed aflatoxin concentration level in conformity with the European standard ( $4 \mathrm{ppb}$ ). Out of three clusters revealed by hierarchical classification based on disease incidence and severity, the cluster 1 contained 33 genotypes characterised by low incidence and severity values. These genotypes can be tested under field conditions to confirm their resistance to A flavus.
\end{abstract}

\section{Introduction}

Peanut (Arachis hypogaea L.) is an important staple crop in Senegal. The national peanut production was estimated at $1,050,042$ tons during the rainy season of 2016 [1]. This crop is mainly produced in Fatick, Kaolack, Kaffrine, Louga, and Thies regions, with more than $60 \%$ of the national peanut production [1]. Peanut seeds are widely used for food consumption and play a significant economic role for smallscale farmers and food industries in Senegal [2]. However, pre- and postharvest aflatoxin contamination in peanut is a serious threat for food safety and human health in Senegal [3]. It is one of the major constraints limiting sustainable and good quality seed production in the world [4]. Aflatoxin contamination is due to Aspergillus flavus (Link ex Fries, Teleomorph: Petromyces flavus) [5]. Damages caused by this facultative plant pathogen in maize, peanut, and sesame were reported in Senegal [6]. Considerable economic losses caused by this bacterium are mainly due to crop quality value and international trade restrictions on food stuffs charged in aflatoxin [7].

Aflatoxin is the name of a group of toxin known as G1, G2, B1, B2, M1, and M2 that produced the plant pathogen [8]. These toxins occur naturally and have been found in a wide range of commodities, including peanuts used for animal and human consumption [9]. Aflatoxins are toxic, mutagenic, and carcinogenic compounds [10]. Depending on their levels, toxins can severely affect the liver and induce immune-suppressing effects [9].

To handle this issue, a wide range of preharvest aflatoxin contamination management methods were developed. Application of atoxinogenic isolates of A. flavus [11] and 
host genetic resistance were tested [12]. In Senegal, previous studies reported that varieties 55-437 and 73-3 were resistant to A. flavus [13]. Identification of new sources of resistance merits to be investigated for efficient peanut breeding program. First step of host genetic resistance is the seed colonization test. Therefore, the present study was undertaken to identify promising peanut genotypes under laboratory conditions.

\section{Materials and Methods}

2.1. Plant Materials. The plant material consisted of 67 genotypes including 58 chromosomal substitutions lines [14] and nine national released varieties. The chromosomal substitution lines belong to a cross between Fleur 11 and a synthetic amphidiploid parent (Table 1).

2.2. Isolation of Aspergillus flavus, Sporangial Suspension Preparation, and Inoculation. Aflatoxinogenic strain provided from peanut seeds were purified by successive cultures on 5/2 agar medium. The aflatoxin concentration level was checked using the Reveal ${ }^{\circledR} \mathrm{Q}^{+}$Aflatoxin test kit (accesso peanut enterprise corporation, USA). The spore suspension of $A$. flavus was obtained by soaking colonized seeds in $50 \mathrm{ml}$ of sterile distilled water. Then, one drop of Tween 20 was added to the solution and thoroughly mixed for 10 minutes. Inoculation was carried out by introducing $100 \mu \mathrm{l}$ of the supernatant of the spore suspension into each Petri dish.

2.3. Seed Colonization Test. The seed colonization test was conducted following a modified Mehan and McDonald procedure. For each genotype, 50 seeds were sterilized and rinsed properly in sterile distilled water. Then, the seeds were hydrated to about $20 \%$ moisture content. The 50 seeds of each genotype were placed in 5 Petri dishes containing 10 seeds, and each Petri dish was considered as a replication. The seeds were inoculated with a conidial suspension $(60 \mu \mathrm{L}$ containing approximately $1 \times 10^{8} \mathrm{~mL}^{-1}$ conidia of the aflatoxigenic strain of $A$. flavus). This preparation was kept at laboratory conditions $\left(25 \pm 0.12^{\circ} \mathrm{C}\right.$ and $82 \pm 0.42 \%$ relative humidity) for fifteen days.

2.4. Data Collection. The seeds' colonization was observed during two weeks, and aflatoxin concentration was measured using the Reveal ${ }^{\circledR} \mathrm{Q}^{+}$Aflatoxin test kit (accesso peanut enterprise corporation, USA). The incidence was calculated using the following formula:

$$
\begin{aligned}
\text { incidence }(\%) & \\
= & \frac{\text { number of seeds showing pathogen colonizaton }}{\text { total number of seeds }} \\
& \times 100 .
\end{aligned}
$$

\begin{tabular}{|c|c|c|c|}
\hline No & Genotypes & Description & Country of origin \\
\hline 1 & 12CS_001 & CSL $^{*}$ & Senegal \\
\hline 2 & 12CS_004 & CSL & Senegal \\
\hline 3 & 12CS_006 & CSL & Senegal \\
\hline 4 & 12CS_007 & CSL & Senegal \\
\hline 5 & 12CS_008 & CSL & Senegal \\
\hline 6 & 12CS_009 & CSL & Senegal \\
\hline 7 & 12CS_010 & CSL & Senegal \\
\hline 8 & 12CS_011 & CSL & Senegal \\
\hline 9 & 12CS_012 & CSL & Senegal \\
\hline 10 & 12CS_016 & CSL & Senegal \\
\hline 11 & 12CS_018 & CSL & Senegal \\
\hline 12 & 12CS_020 & CSL & Senegal \\
\hline 13 & 12CS_021 & CSL & Senegal \\
\hline 14 & 12CS_022 & CSL & Senegal \\
\hline 15 & 12CS_023 & CSL & Senegal \\
\hline 16 & 12CS_024 & CSL & Senegal \\
\hline 17 & 12CS_027 & CSL & Senegal \\
\hline 18 & 12CS_028 & CSL & Senegal \\
\hline 19 & 12CS_031 & CSL & Senegal \\
\hline 20 & 12CS_032 & CSL & Senegal \\
\hline 21 & 12CS_033 & CSL & Senegal \\
\hline 22 & 12CS_034 & CSL & Senegal \\
\hline 23 & 12CS_036 & CSL & Senegal \\
\hline 24 & 12CS_037 & CSL & Senegal \\
\hline 25 & 12CS_039 & CSL & Senegal \\
\hline 26 & 12CS_041 & CSL & Senegal \\
\hline 27 & 12CS_042 & CSL & Senegal \\
\hline 28 & 12CS_047 & CSL & Senegal \\
\hline 29 & 12CS_048 & CSL & Senegal \\
\hline 30 & 12CS_050 & CSL & Senegal \\
\hline 31 & 12CS_051 & CSL & Senegal \\
\hline 32 & 12CS_052 & CSL & Senegal \\
\hline 33 & 12CS_053 & CSL & Senegal \\
\hline 34 & 12CS_054 & CSL & Senegal \\
\hline 35 & 12CS_055 & CSL & Senegal \\
\hline 36 & 12CS_059 & CSL & Senegal \\
\hline 37 & 12CS_060 & CSL & Senegal \\
\hline 38 & 12CS_061 & CSL & Senegal \\
\hline 39 & 12CS_062 & CSL & Senegal \\
\hline 40 & 12CS_063 & CSL & Senegal \\
\hline 41 & 12CS_066 & CSL & Senegal \\
\hline 42 & 12CS_070 & CSL & Senegal \\
\hline 43 & 12CS_072 & CSL & Senegal \\
\hline 44 & 12CS_075 & CSL & Senegal \\
\hline 45 & 12CS_076 & CSL & Senegal \\
\hline 46 & 12CS_078 & CSL & Senegal \\
\hline 47 & 12CS_079 & CSL & Senegal \\
\hline 48 & 12CS_084 & CSL & Senegal \\
\hline 49 & 12CS_085 & CSL & Senegal \\
\hline 50 & 12CS_090 & CSL & Senegal \\
\hline 51 & 12CS_091 & CSL & Senegal \\
\hline 52 & 12CS_095 & CSL & Senegal \\
\hline 54 & 12CS_096 & CSL & Senegal \\
\hline 55 & 12CS_100 & CSL & Senegal \\
\hline 56 & 12CS_111 & CSL & Senegal \\
\hline 57 & 12CS_112 & CSL & Senegal \\
\hline 58 & 12CS_118 & CSL & Senegal \\
\hline 59 & 12CS_119 & CSL & Senegal \\
\hline 60 & $55-33$ & Variety & Senegal \\
\hline 61 & $55-437$ & Resistant control & Senegal \\
\hline
\end{tabular}

Table 1: Peanut material used in this study. 
TABle 1: Continued.

\begin{tabular}{lccc}
\hline No & Genotypes & Description & Country of origin \\
\hline 62 & $73-30$ & CSL & Senegal \\
63 & $73-33$ & Resistant control & Senegal \\
64 & $78-936$ & Variety & Senegal \\
65 & Fleur11 & Susceptible control & Senegal \\
66 & GC-8-35 & Variety & Senegal \\
67 & L27 & Variety & Senegal \\
\hline
\end{tabular}

${ }^{*}$ Chromosomal substitution lines.

The severity scale of aflatoxin on seeds was estimated using a modified Tonapi et al. [15] scale. It was defined as follows: 0 , noninfected seeds; 1 , seeds whose surface covered by the fungus is less than $20 \% ; 2,20 \%-40 \%$ seed surface covered by the fungus; $3,40 \%-60 \%$ seed surface covered by the fungus; $4,60 \%-80 \%$ seed surface covered by the fungus; and $5,80 \%-100 \%$ seed surface covered by the fungus. The severity calculation based on Tonapi et al. [15] formula was as follows:

$$
\operatorname{severity}(\%)=\frac{\sum_{i=1}^{n}\left(N_{i} \times i\right)}{\text { total of seeds } \times(n-1)},
$$

where $p<0.001 i$ is severity scale from 0 to 5 and $N_{i}$ is the number of seed corresponding to scale $i$ of severity.

2.5. Data Analysis. Data analysis was performed with the open-source statistical software $\mathrm{R}$ version 3.4 .5 [16]. Descriptive statistics of recorded data were generated with pastecs package [17]. In order to find out variability of incidence and severity according to tested genotypes, data were subjected to Poisson regression analysis using glm (generalized linear model) function of package stats implemented in the R. Spearman's rank correlation test was performed to highlight relationship between incidence, severity, and aflatoxin concentration levels using correlation test function of package stats. Identification of different groups of genotypes based on incidence and severity was performed based on a principal component analysis and a hierarchical clustering with the functions PCA and HCPC of package FactoMineR [18], respectively. The Euclidean distance and Ward classification method were used to classify tested genotypes. The function fviz_pca_biplot [19] was used to plot the principal components analysis biplot in different clusters based on hierarchical classification.

\section{Results}

3.1. Reaction of Peanut Genotypes to Aspergillus flavus. Analysis of variance revealed highly significant $(p<0.001)$ variation of aflatoxin incidence and severity among the tested peanut genotypes (Table 2).

The severity ranged between 0 and $44 \%$, respectively, with a mean of $8.82 \pm 0.45 \%$. The recorded incidence ranged from 0 to $70 \%$ with an average value of $20.36 \pm 0.80 \%$ (Table 3).

One genotype (12CS_104) showed aflatoxin concentration level less than $4 \mathrm{ppb}$. A total of 34 genotypes
TABle 2: Deviance values from the Poisson regression model on incidence and severity.

\begin{tabular}{lccc}
\hline Source of variation & Degree of freedom & Incidence & Severity \\
\hline Replication & 4 & $33.9(\mathrm{~ns})$ & $2.04(\mathrm{~ns})$ \\
Genotype & 66 & $7242.2^{* * *}$ & $190.08^{* * *}$ \\
\hline${ }^{* * *}$ Significant & chi-squared test at 0.001 & level of probability; ns $=$ not \\
significant. & & &
\end{tabular}

presented aflatoxin concentration level up to $2000 \mathrm{ppb}$ (Figure 1).

Out of the 67 genotypes, eight showed incidence less than $10 \%$ while 33 showed incidences between 10 and $20 \%$ and 16 with incidences ranged from 20 to $30 \%$ (Figure 2).

3.2. Correlation between Incidence, Severity, and Aflatoxin Concentration Level. Spearman's rank correlation test revealed a strong relationship $(r=0.93, p<0.001)$ between incidence and severity of peanut genotypes. Positive and significant correlations were detected between aflatoxin concentration levels and disease incidence $(r=0.28$, $p<0.01)$ and aflatoxin concentration levels and disease severity $(r=0.35, p<0.05)$ (Table 4$)$.

3.3. Classification of the Tested Genotypes according to Sensibility and Aflatoxin Concentration Level. The factorial axes 1 and 2 explained 60.5 and $39.5 \%$ of overall variability, respectively (Figure 3 ). Hierarchical classification performed on principal component analysis revealed three clusters of genotypes based on disease incidence and aflatoxin concentration levels (Figure 3). The clusters 1, 2, and 3 grouped 33,20 , and 14 genotypes, respectively. The incidence and aflatoxin concentration are significantly $(p<0.001)$ associated to cluster 1 (Table 4).

Mean values of these two variables in this cluster are less than the overall mean. Therefore, cluster 1 is characterized by desirable genotypes which combine low incidence values and aflatoxin concentration levels. Cluster 2 is significantly $(p<0.001)$ related to the aflatoxin concentration level (Table 5).

The mean value of aflatoxin concentration in cluster 2 ( $4075.5 \mathrm{ppb}$ ) is $190 \%$ which is higher than the overall mean (2143.8 ppb). Thus, this second cluster is characterized by genotypes with high level of aflatoxin. Incidence is linked to cluster 3 (Table 5). Mean value of this variable (35\%) in cluster 3 is superior to overall mean $(20.35 \%)$. Thus, the cluster 3 encompasses the most susceptible genotypes to $A$. flavus.

Based on the closest distance between each genotype and the respective cluster centres, 12CS_039, 12CS_010, and 12CS_050 were the first representative genotypes (paragon) of cluster 1,2, and 3, respectively (Table 4). Based on the farthest distance from a genotype projected point in a cluster to the centres of the two others, clustering revealed that cluster 1,2 , and 3 were characterised by the genotypes 12CS_104, 78-936, and 12CS_021, respectively (Figure 3, Table 5). Based on results, out of 67 genotypes, 33 promising genotypes (cluster 1) were noted (Figure 3 ). 
TABle 3: Means of incidence and severity of the tested lines.

\begin{tabular}{|c|c|c|c|c|}
\hline \multirow{2}{*}{ Lines } & \multicolumn{2}{|c|}{ Incidence } & \multicolumn{2}{|r|}{ Severity } \\
\hline & Mean & Std deviation & Mean & Std deviation \\
\hline 12CS_001 & 44 & 13.42 & 1.02 & 0.44 \\
\hline 12CS_004 & 30 & 12.25 & 0.74 & 0.23 \\
\hline 12CS_006 & 30 & 15.81 & 0.46 & 0.29 \\
\hline 12CS_007 & 18 & 8.37 & 0.34 & 0.21 \\
\hline 12CS_008 & 12 & 16.43 & 0.22 & 0.27 \\
\hline 12CS_009 & 24 & 8.94 & 0.58 & 0.33 \\
\hline 12CS_010 & 18 & 8.37 & 0.4 & 0.27 \\
\hline 12CS_011 & 18 & 14.83 & 0.42 & 0.48 \\
\hline 12CS_012 & 32 & 13.04 & 0.82 & 0.43 \\
\hline 12CS_016 & 34 & 8.94 & 0.82 & 0.54 \\
\hline 12CS_018 & 38 & 13.04 & 0.66 & 0.33 \\
\hline 12CS_020 & 22 & 10.95 & 0.5 & 0.34 \\
\hline 12CS_021 & 52 & 10.95 & 1.64 & 0.49 \\
\hline 12CS_022 & 16 & 15.17 & 0.36 & 0.43 \\
\hline 12CS_023 & 18 & 13.04 & 0.28 & 0.24 \\
\hline 12CS_024 & 28 & 10.95 & 0.5 & 0.21 \\
\hline 12CS_027 & 18 & 8.37 & 0.26 & 0.19 \\
\hline 12CS_028 & 18 & 8.37 & 0.3 & 0.20 \\
\hline 12CS_031 & 16 & 5.48 & 0.4 & 0.28 \\
\hline 12CS_032 & 14 & 11.40 & 0.16 & 0.11 \\
\hline 12CS_033 & 10 & 12.25 & 0.2 & 0.23 \\
\hline 12CS_034 & 14 & 15.17 & 0.28 & 0.34 \\
\hline 12CS_036 & 14 & 5.48 & 0.26 & 0.15 \\
\hline 12CS_037 & 16 & 5.48 & 0.32 & 0.19 \\
\hline 12CS_039 & 14 & 8.94 & 0.22 & 0.23 \\
\hline 12CS_041 & 24 & 15.17 & 0.64 & 0.38 \\
\hline 12CS_042 & 24 & 18.17 & 0.42 & 0.42 \\
\hline 12CS_047 & 18 & 13.04 & 0.4 & 0.22 \\
\hline 12CS_048 & 6 & 8.94 & 0.08 & 0.13 \\
\hline 12CS_050 & 34 & 11.40 & 0.76 & 0.29 \\
\hline 12CS_051 & 34 & 20.74 & 0.72 & 0.36 \\
\hline 12CS_052 & 30 & 15.81 & 0.76 & 0.67 \\
\hline 12CS_053 & 36 & 15.17 & 0.98 & 0.59 \\
\hline 12CS_054 & 26 & 11.40 & 0.68 & 0.44 \\
\hline 12CS_055 & 18 & 8.37 & 0.48 & 0.54 \\
\hline 12CS_059 & 24 & 16.73 & 0.48 & 0.48 \\
\hline 12CS_060 & 12 & 13.04 & 0.4 & 0.39 \\
\hline 12CS_061 & 14 & 11.40 & 0.24 & 0.19 \\
\hline 12CS_062 & 18 & 8.37 & 0.26 & 0.15 \\
\hline 12CS_063 & 18 & 14.83 & 0.42 & 0.53 \\
\hline 12CS_066 & 32 & 22.80 & 0.8 & 0.76 \\
\hline 12CS_070 & 22 & 19.24 & 0.56 & 0.53 \\
\hline 12CS_072 & 14 & 13.42 & 0.26 & 0.28 \\
\hline 12CS_075 & 28 & 13.04 & 0.66 & 0.36 \\
\hline 12CS_076 & 12 & 4.47 & 0.18 & 0.08 \\
\hline 12CS_078 & 10 & 12.25 & 0.16 & 0.18 \\
\hline 12CS_079 & 18 & 16.43 & 0.34 & 0.34 \\
\hline 12CS_084 & 14 & 5.48 & 0.3 & 0.21 \\
\hline 12CS_085 & 22 & 8.37 & 0.5 & 0.32 \\
\hline 12CS_090 & 14 & 13.42 & 0.34 & 0.50 \\
\hline 12CS_091 & 26 & 11.40 & 0.64 & 0.48 \\
\hline 12CS_095 & 12 & 8.37 & 0.26 & 0.27 \\
\hline 12CS_096 & 16 & 8.94 & 0.48 & 0.58 \\
\hline 12CS_100 & 40 & 12.25 & 0.96 & 0.34 \\
\hline 12CS_104 & 6 & 8.94 & 0.14 & 0.26 \\
\hline 12CS_111 & 6 & 8.94 & 0.1 & 0.14 \\
\hline 12CS_112 & 18 & 16.43 & 0.26 & 0.32 \\
\hline 12CS_118 & 20 & 10.00 & 0.3 & 0.20 \\
\hline 12CS_119 & 20 & 7.07 & 0.42 & 0.28 \\
\hline
\end{tabular}

TABLE 3: Continued.

\begin{tabular}{|c|c|c|c|c|}
\hline \multirow{2}{*}{ Lines } & \multicolumn{2}{|c|}{ Incidence } & \multicolumn{2}{|c|}{ Severity } \\
\hline & Mean & Std deviation & Mean & Std deviation \\
\hline $55-33$ & 4 & 5.48 & 0.04 & 0.05 \\
\hline $55-437$ & 12 & 10.95 & 0.18 & 0.19 \\
\hline $73-30$ & 6 & 5.48 & 0.06 & 0.05 \\
\hline $73-33$ & 16 & 11.40 & 0.28 & 0.19 \\
\hline 78-936 & 12 & 4.47 & 0.24 & 0.31 \\
\hline Fleur_11 & 28 & 16.43 & 0.5 & 0.17 \\
\hline GC-8-35 & 22 & 10.95 & 0.6 & 0.24 \\
\hline L27 & 10 & 0.00 & 0.16 & 0.13 \\
\hline Mean & \multicolumn{2}{|r|}{20.36} & \multicolumn{2}{|r|}{8.82} \\
\hline Standard error & \multicolumn{2}{|r|}{0.80} & \multicolumn{2}{|r|}{0.45} \\
\hline
\end{tabular}

TABLE 4: Spearman's rank matrix correlation performed on incidence, severity, and aflatoxin concentration levels data.

\begin{tabular}{lccc}
\hline & Incidence & Severity & $\begin{array}{c}\text { Aflatoxin } \\
\text { concentration levels }\end{array}$ \\
\hline $\begin{array}{l}\text { Incidence } \\
\text { Severity }\end{array}$ & 1.00 & & \\
$\begin{array}{l}\text { Aflatoxin } \\
\text { concentration levels }\end{array}$ & $0.93^{* * *}$ & 1.00 & 1.00 \\
\hline * Significant Spearman's rank correlation test at 0.05 level of probability. \\
** Significant Spearman's rank correlation test at 0.01 level of probability. \\
*** Significant Spearman's rank correlation test at 0.001 level of probability.
\end{tabular}

\section{Discussion}

In the present study, a wide phenotypic variation was observed among the tested genotypes for incidence, severity, and aflatoxin concentrations. This variation can be explained by the variability of seed coat structure of the tested genotypes. In fact, the seed coat can constitute a barrier to $A$. flavus seed invasion depending on its thickness and/or permeability [20], and Zhou and Liang [21] studies showed that genotypes seed coat with smaller hilum, more compact arrangement and thicker testa showed more resistance to A. flavus. In addition, implication of wax and cutin layers of seed coat was demonstrated to be related to genotypes resistance [22]. Another explanation of this wide variation in incidence, severity, and aflatoxin rate can be biochemical compounds' differential variability in the tested seeds. Lindsey and Turner [23] demonstrated that the presence of polyphenol compounds, specifically, tannins in seed can have inhibitor effect against $A$. flavus. Amaya et al. [24] and Liang et al. [25] showed the difference among seed coat biochemical compounds to determine sensibility to $A$. flavus. Liang [22] demonstrated that the presence of trypsin in seeds can also be related to resistance to A. flavus. Turner et al. [26] isolated and identified the 5,7-dimethoxyisoflavone as an inhibitor for A. flavus invasion in peanut seed.

12CS_104 was the most resistant genotype to aflatoxin contamination with an aflatoxin level lower than the European Union standards (4 ppb). However, except 12CS_104, all the genotypes have their aflatoxin concentration level higher than the Chinese $(20 \mathrm{ppb})$ standards. 


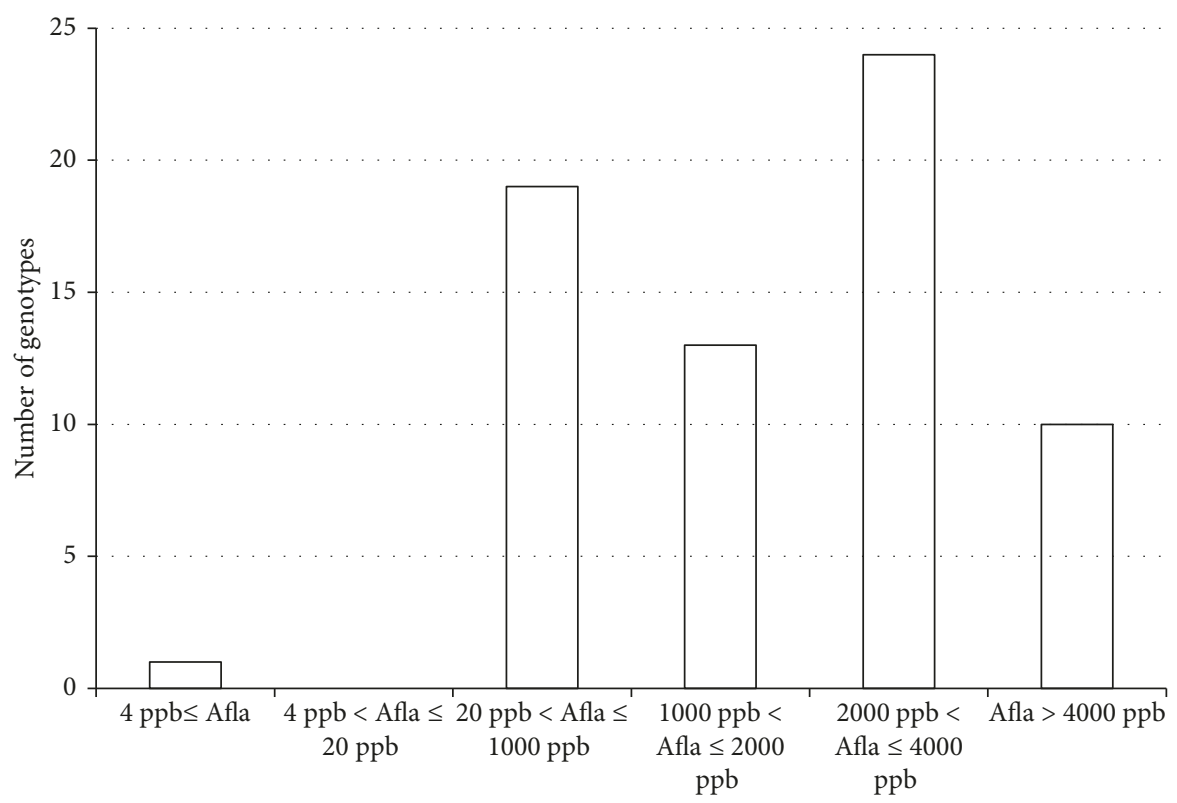

Figure 1: Number of peanut genotypes according to aflatoxin concentration level interval values.

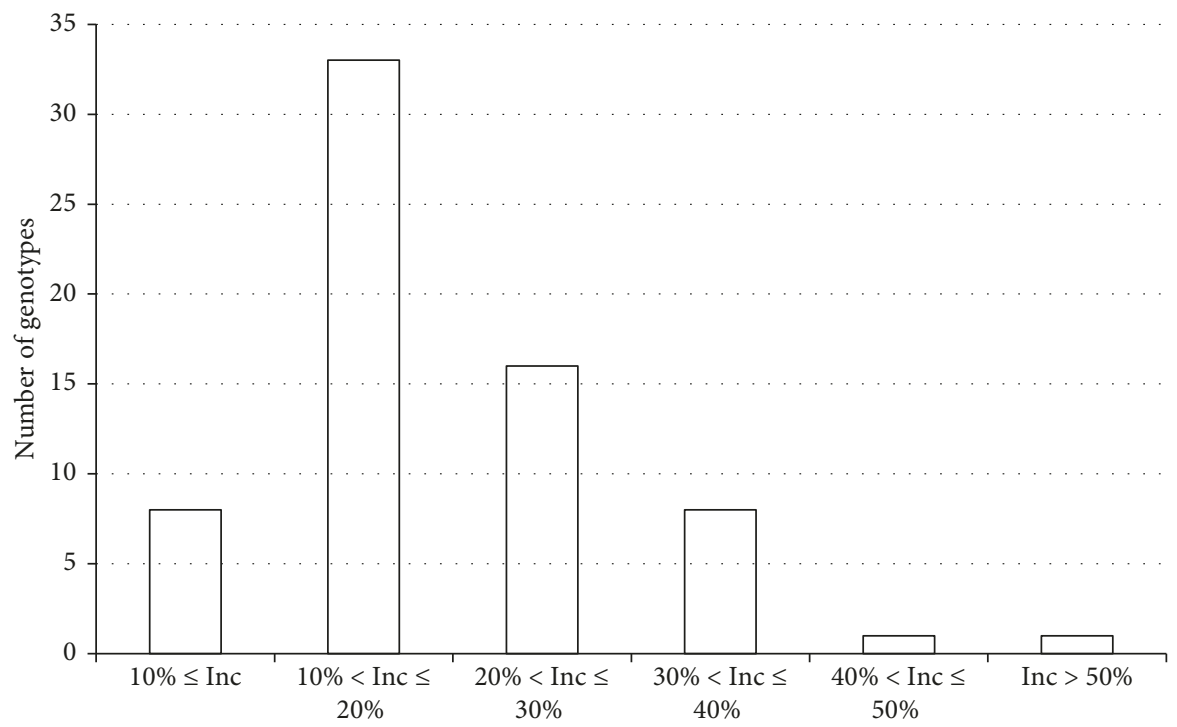

Figure 2: Number of peanut genotypes showing aflatoxin presence according to incidence intervals.

Indeed, the highest aflatoxin concentration level was observed with genotype 78-936. The contrasting genotypes observed in this study can be used as positive and negative checks, respectively, for accurate field experiment. Furthermore, these contrasted genotypes can be used to develop mapping population for genetic study such as inheritance of aflatoxin and identification of quantitative trait loci (QTL). The varieties 55-437 and 73-30 showed incidence less than $15 \%$ as reported by the previous study realized 30 years ago by Zambettakis et al. [13], but their aflatoxin concentration levels were largely up to the European Union standards.

The correlation test showed a positive relationship between A. flavus colonization and aflatoxin contamination.
This confirmed that the presence of A. flavus induced aflatoxin production in seeds. Hierarchical classification highlighted three clusters according to incidence, severity, and aflatoxin concentration levels. The relatively low values of incidence observed on the 33 genotypes belonged to cluster 1 should be confirmed under field conditions. These genotypes can be evaluated in different locations on infested fields.

\section{Conclusion}

This study uncovered that the lines 12CS_104 exhibited low values of incidence and severity. Furthermore, its aflatoxin 

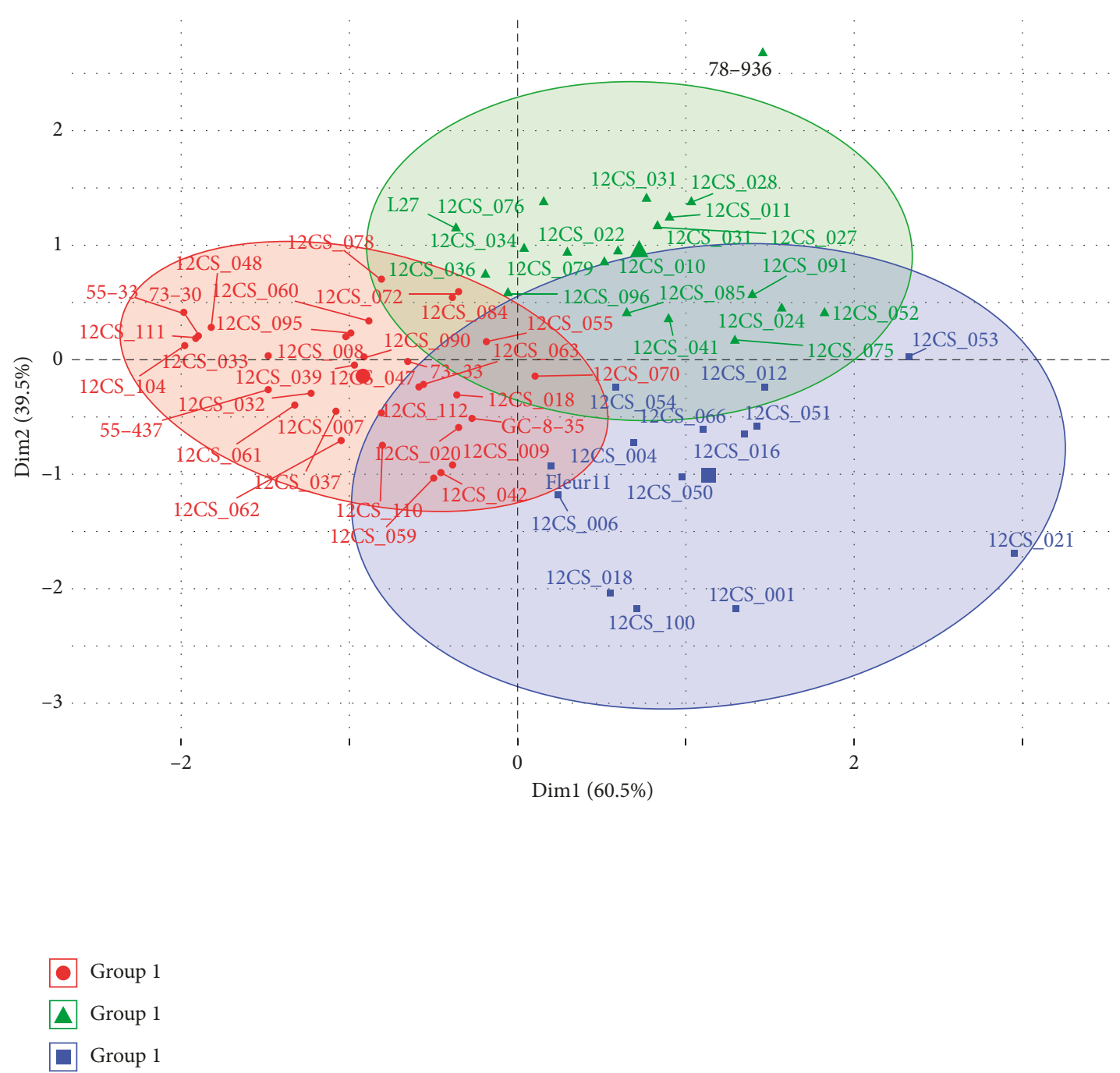

Figure 3: Principal component analysis biplot showing peanut genotypes clustering based on their severity and incidence.

TABLE 5: Description of each cluster based on incidence, aflatoxin concentration levels, and paragon and singular genotype per cluster.

\begin{tabular}{|c|c|c|c|c|c|c|c|c|c|}
\hline & \multicolumn{3}{|c|}{ Cluster 1} & \multicolumn{3}{|c|}{ Cluster 2} & \multicolumn{3}{|c|}{ Cluster 3} \\
\hline & Mean & $\begin{array}{c}\text { Overall } \\
\text { mean }\end{array}$ & $p$ value $^{\dagger}$ & Mean & $\begin{array}{l}\text { Overall } \\
\text { mean }\end{array}$ & $p$ value & Mean & $\begin{array}{l}\text { Overall } \\
\text { mean }\end{array}$ & $p$ value \\
\hline \multicolumn{10}{|c|}{ Description of clusters by variables } \\
\hline Incidence & 15.09 & 20.35 & $<10^{-3}$ & 18.8 & 20.35 & $>0.05$ & 35.00 & 20.35 & $<10^{-3}$ \\
\hline Aflatoxin & 915.65 & 2143.89 & $<10^{-3}$ & 4075.50 & 2143.89 & $<10^{-3}$ & 2279.57 & 2143.89 & $>0.05$ \\
\hline \multicolumn{10}{|c|}{ Description of clusters by distances } \\
\hline $\begin{array}{l}\text { Top } 3 \text { representative } \\
\text { genotypes }\end{array}$ & $\begin{array}{c}\text { 12CS_039 } \\
(0.11)\end{array}$ & $\begin{array}{c}\text { 12CS_090 } \\
(0.16)\end{array}$ & $\begin{array}{l}73-33 \\
(0.29)\end{array}$ & $\begin{array}{c}\text { 12CS_010 } \\
(0.12)\end{array}$ & $\begin{array}{c}\text { 12CS_079 } \\
(0.22)\end{array}$ & $\begin{array}{c}\text { 12CS_027 } \\
(0.24)\end{array}$ & $\begin{array}{c}12 \mathrm{CS} \_050 \\
(0.15)\end{array}$ & $\begin{array}{c}\text { 12CS_066 } \\
(0.41)\end{array}$ & $\begin{array}{c}\text { 12CS_016 } \\
(0.42)\end{array}$ \\
\hline $\begin{array}{l}\text { Top } 3 \text { characteristic } \\
\text { genotypes }^{\dagger \dagger}\end{array}$ & $\begin{array}{c}\text { 12CS_104 } \\
(2.82)\end{array}$ & $\begin{array}{l}55-33 \\
(2.75)\end{array}$ & $\begin{array}{c}\text { 12CS_111 } \\
(2.74)\end{array}$ & $\begin{array}{c}78-936 \\
(3.68)\end{array}$ & $\begin{array}{c}\text { 12CS_028 } \\
(2.39)\end{array}$ & $\begin{array}{c}\text { 12CS_031 } \\
(2.28)\end{array}$ & $\begin{array}{l}\text { 12CS_021 } \\
(3.45)\end{array}$ & $\begin{array}{c}\text { 12CS_001 } \\
(3.00)\end{array}$ & $\begin{array}{c}\text { 12CS_100 } \\
(2.59)\end{array}$ \\
\hline
\end{tabular}

concentration level was smaller than standards. This genotype represents a relevant tool for the breeding program for resistance to A. flavus as a potentially resistant gene donor.

\section{Data Availability}

The data used to support the findings of this study are available from the corresponding author upon request. 


\section{Conflicts of Interest}

The authors declare no conflicts of interest regarding the publication of this paper.

\section{Acknowledgments}

The authors sincerely thank the West Africa Agricultural Productivity Program (WAAPP) for financial support and facilities help.

\section{References}

[1] ANSD, Bulletin Mensuel des Statistiques Économiques, ANSD, Dakar, Sénégal, 2017.

[2] D. Clavel, A. Da Sylva, O. Ndoye, and A. Mayeux, "Amélioration de la qualité sanitaire de l'arachide au Sénégal: un challenge pour une opération de recherche dévelopement participative," Cahiers Agricultures, vol. 22, no. 13, pp. 174-81, 2013.

[3] P. M. Diedhiou, F. Ba, A. Kane, and N. Mbaye, "Effect of different cooking methods on aflatoxin fate in peanut products," African Journal of Food Science and Technology, vol. 3, no. 12, pp. 53-58, 2012.

[4] W. A. Korani, Y. Chu, C. Holbrook, J. Clevenger, and P. Osias Akins, "Genotypic regulation of aflatoxin accumulation but not Aspergillus fungal growth upon post-harvest infection of peanut (Arachis hypogaea L.) seeds," Toxins, vol. 9, no. 7, p. E218, 2017.

[5] J. C. Fountain, J. Koh, L. Yang et al., "Proteome analysis of Aspergillus flavus isoate-specific responses to oxidative stress in relationship to aflatoxin production capability," Scientic Reports, vol. 8, no. 1, p. 3430, 2018.

[6] P. M. Diedhiou, R. Bandyopadhyay, J. Atehnkeng, and P. S. Ojiambo, "Aspergillus colonization and aflatoxin contamination of maize and sesame kernels in two agro-ecoloical zones in Senegal," Journal of Phytopathology, vol. 159, no. 4, pp. 268-275, 2011.

[7] X. Q. Liang, M. Luo, and B. Z. Guo, "Resistance mechanisms to Aspergillus flavus infection and aflatoxin contamination in peanut (Arachis hypogea L.)," Plant Pathology Journal, vol. 5, no. 11, pp. 115-124, 2006.

[8] S. Amaike and N. P. Keller, "Aspergillus flavus," Annual Review of Phytopathology, vol. 49, no. 1, pp. 107-133, 2011.

[9] J. H. Williams, T. D. Phillips, P. Jolly, J. K. Styles, C. M. Jolly, and D. Aggarwal, "Human aflatoxicosis in developing countries: a review of toxicology, exposure, potential health consequences, and interventions," American Journal of Clinical Nutrition, vol. 80, no. 5, pp. 1106-1122, 2004.

[10] Y. C. Chen, C. D. Liao, H. Y. Lin, L. C. Chiueh, and D. Y. C. Shih, "Survey of aflatoxin contamination in peanut proucts in Taiwan from 1997 to 2011," Journal of Food and Drug Analysis, vol. 21, no. 3, pp. 247-252, 2013.

[11] R. Y. Kelley, W. P. Williams, J. E. Mylroie et al., "Identification of maize genes associated with host plant resistance or susceptibility to Aspergillus flavus infection and aflatoxin accumulation," PLoS ONE, vol. 7, no. 5, Article ID e36892, 2012.

[12] H. Q. Xue, T. G. Isleib, G. A. Payne, and G. OBrian, "Evaluation of post-harvest aflatoxin production in peanut germplasm with resistance to seed colonization and preharvest aflatoxin contamination," Peanut Science, vol. 31, no. 2, pp. 124-134, 2004.

[13] C. Zambettakis, F. Waliyar, A. Bockelee-Morvan, and O. de Pins, "Results of four years of research on resistance of groundnut varieties to Aspergillus flavus," Oleagineux, vol. 36, pp. 377-385, 1981.
[14] D. Fonceka, H. A. Tossim, R. Rivallan et al., "Construction of chromosome segment substitution lines in peanut (Arachis hypogea L.) using a wild synthetic and QTL mapping for plant morphology," Plos ONE, vol. 7, no. 11, Article ID e48642, 2012.

[15] V. K. Mehan and D. McDonald, Screening for Resistance to Aspergillus Invasion and Aflatoxin Production in Groundnuts, ICRISAT Groundnut Improvement Program Occasional Paper2, Patancheru, India, 1980.

[16] V. A. Tonapi, R. R. Mundada, S. S. Navi et al., "Effect of temperature and humidity regimes on grain mold sporulation and seed quality in sorghum (Sorghum bicolor (L.) Moench)," Archives of Phytopathology and Plant Protection, vol. 40, no. 2, pp. 113-127, 2007.

[17] R Core Team, A Language and Environment for Statistical Computing, R Foundation for Statistical Computing, Vienna, Austria, 2018.

[18] P. Grosjean and F. Ibanez, PASTECS: Package for Analysis of Space Time Ecological Series, R package version 1.3-18, 2014.

[19] S. Lê, J. Josse, and F. Husson, "FactoMineR: an R package for multivariate analysis," Journal of Statistical Software, vol. 25, no. 1, pp. 1-18, 2008.

[20] A. Kassambara and F. Mundt, factoextra: Extract and visualize the results of multivariate data analyses. $R$ package version 1.0.4, 2017.

[21] R. A. Taber, R. E. Pettit, C. R. Benedict, J. W. Dieckert, and D. L. Kertrin, "Comparison of Aspergillus flavus tolerant and susceptible lines. I. Light microscope investigation," in Proceedings of the American Peanut Research Education Association, vol. 5, pp. 206-207, Oklahoma, USA, 1973.

[22] G. Y. Zhou and X. Q. Liang, "Studies on the ultramicroscopic structure of seed coats between resistant and susceptible to Aspergillus flavus invasion in peanut," Chinese Journal of Oil Crop Sciences, vol. 20, pp. 32-35, 1999.

[23] X. Q. Liang, G. Y. Zhou, and R. Z. Pan, "Study on the relationship of wax and cutin layers in peanut seeds and resistance to invasion and aflatoxin production by Aspergillus flavus," Journal Of Tropical And Subtropical Botany, vol. 11, pp. 11-14, 2003.

[24] D. L. Lindsey and R. B. Turner, "Inhibition of growth of Aspergillus flavus and Trichoderma viride by peanut embryos," Mycopathologia, vol. 55, no. 3, pp. 149-152, 1975.

[25] F. J. Amaya, C. T. Young, A. J. Norden, and A. C. Mixon, "Chemical screening for Aspergillus flavus resistance in peanut," Oleagineux, vol. 35, no. 5, pp. 255-259, 1980.

[26] X. Q. Liang, G. Y. Zhou, and R. Z. Pan, "Changes of some biochemical substances in peanut seeds under infection of Aspergillus flavus and their role in resistance to seed invasion," Chinese Journal of Oil Crop Sciences, vol. 23, no. 2, pp. 26-31, 2001. 


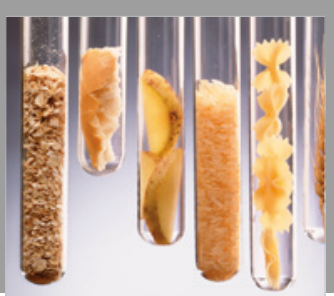

International Journal of Food Science

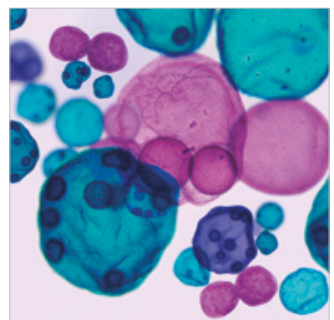

International Journal of Microbiology
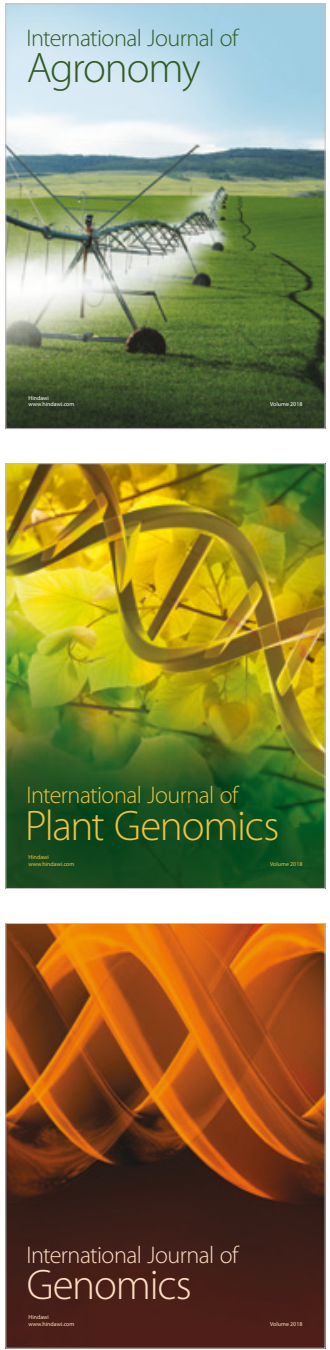

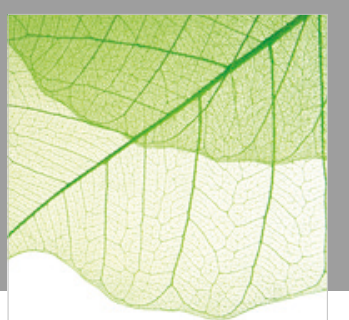

Journal of Botany
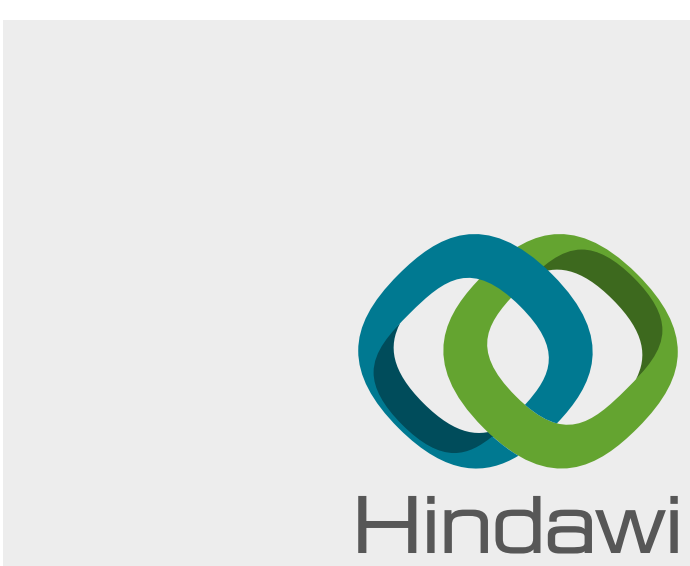

Submit your manuscripts at

www.hindawi.com
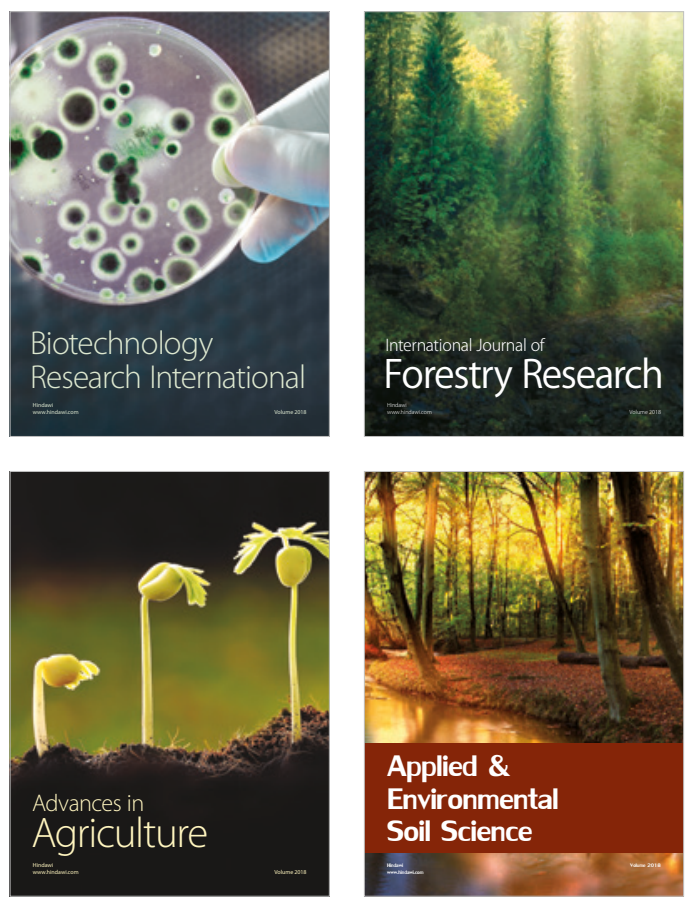

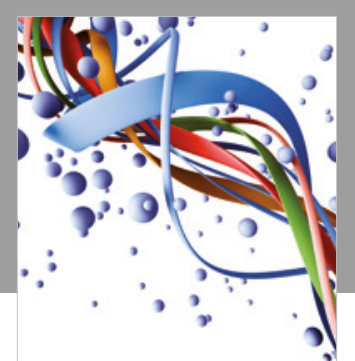

Scientifica

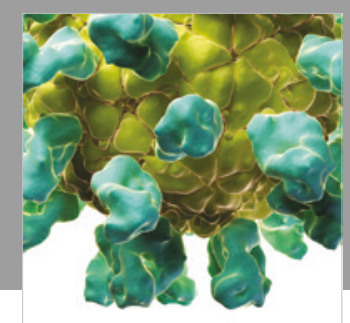

Veterinary Medicine International

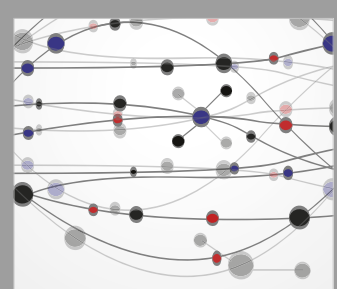

The Scientific World Journal
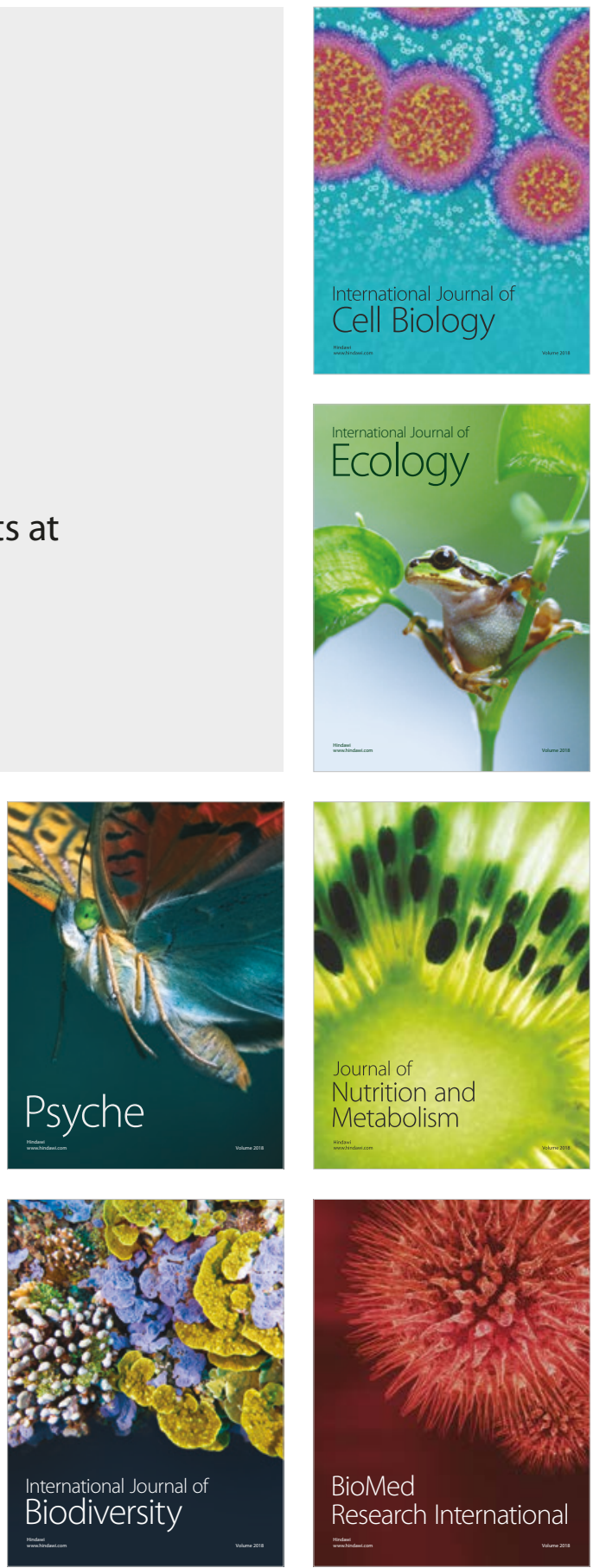